\title{
A Study on the Evaluation Method of Autonomous Vehicle for Fixed Targets
}

\section{Bong-Ju Kim}

Keimyung University https://orcid.org/0000-0003-3954-1245

Seon-Bong Lee ( $\nabla$ seonbong@kmu.ac.kr)

Keimyung University https://orcid.org/0000-0002-8355-1216

\section{Original Article}

Keywords: Autonomous Vehicle, Testing \& Evaluation Method, Fixed target, Scenarios, Actual test

Posted Date: May 18th, 2021

DOI: https://doi.org/10.21203/rs.3.rs-520159/v1

License: (9) This work is licensed under a Creative Commons Attribution 4.0 International License. Read Full License 


\title{
A Study on the Evaluation Method of Autonomous Vehicle for Fixed Targets
}

\author{
Bong-Ju Kim ${ }^{1}$ and Seon-Bong Lee ${ }^{2^{*}}$
}

\begin{abstract}
Recently, the automobile industry aims to commercialize autonomous vehicles, standardization and research and development are actively underway based on the specifications of automotive electronic control systems and the verification of functional errors. Based on this, autonomous driving technology is becoming more advanced, and it is preparing for an era of full autonomous driving through V2X technology convergence. It is also, expanding the models of ADAS applied vehicles such as FCW, BSD, LCA. Based on this, research is also actively underway to secure safety of vehicles and pedestrians, such as V2X, Localization, Fail Safe, to supplement the limitations of sensor-based autonomous driving. In this regard, this study proposes a theoretical formula for longitudinal relative distance computation for autonomous vehicles evaluation method, and uses test device such as DGPS to collects and verify data. In addition, a scenario was proposed for the fixed target, based on this, four types of test were formed to conduct the actual test, and the relative distances were compared, analyzed and verified. Comparative analysis results, in the second test of the first test scenario, the avoidance test of the fixed target in driving own lane, the minimum error rate was $0.5 \%$, and in the second test of fourth test scenario, the avoidance test of the fixed target in driving own lane, the maximum error rate was $7.4 \%$. The main cause of error is, it was judged as an error due to sensor recognition, depending on the scenario progress method, the condition of the test path, and the weather such as sunlight. In the future, we plan to conduct an evaluation on moving target.

Keywords: Autonomous Vehicle, Testing \& Evaluation Method, Fixed target, Scenarios, Actual test
\end{abstract}

\section{Introduction}

The automobile industry recently commercializes autonomous driving, Vehicle electronic control system specifications, functional error verification, etc. Standards and research and development are being actively carried out to analyze potential risk situations of autonomous driving and establish countermeasures. Based on this, the quality of autonomous driving technology is being enhanced, and autonomous driving technology is being developed through Wireless Access in Vehicle Environment (WAVE) communication-based Vehicle to Everything(V2X) technology fusion.

Also, due to the advancement of autonomous driving technology, as a way to consumer's acceptance expansion plan, as the spread of vehicles equipped with advanced driver assist system(ADAS) which a step-by- step approaching method to autonomous driving technology, increases rapidly, autonomous driving technology is being discussed as an important technology to prevent traffic accidents and solving social problems. According to the "GLOBAL STATUS REPORT ON ROAD SAFETY 2018' by the World Health Organization(WHO), with the increase in vehicle supply, there are 1.35 million casualties in traffic accidents per year. Due to human factors(drowsiness, forwardlooking negligence, etc.), it recommends installing advanced driver assistance devices in vehicle to reduce traffic accidents[1]. The New Car Assessment Program(NCAP) standard has been established, to evaluate the safety of these advanced driver assistance device. It was announced that the proposed test be able to increase the safety of the vehicle. To review these grounds, As a result of a survey using the Traffic Accident Analysis System(TAAS), the total population in

* Correspondence : seonbong@kmu.ac.kr

1 Department of Mechanical Engineering, Keimyung University, Daegu, Korea

2 Division of Mechanical and Automotive Engineering, Keimyung University, Daegu, Korea 
South Korea as of 2019 increased $0.2 \%$ year-on-year to $51,709,098$, and vehicle registration increased $1.9 \%$ to $27,500,403$ units. But casualties in traffic accidents decreased by $11.4 \%$ from the previous year, from 3,781 in 2018 to 3,349 in 2019 . It is confirmed as a result of the increase in the installation of advanced driver assistance devices, which are functions level $0 \sim 2$ of autonomous driving of vehicles.

Currently, the automotive industry applies ADAS in vehicle such as Forward Collision Warning(FCW), Autonomous Emergency Braking(AEB), Blind Spot Detection(BSD), Lane Change Assist(LCA), etc. Based on this, research is actively underway to ensure vehicles and pedestrians' safety, such as V2X, Localization, Fail Safe, to compensate for the limitations of sensor-based autonomous driving $[3,4]$.

Regarding autonomous driving technology, the Society of Automotive Engineers(SAE) defines autonomous driving technology in 6 steps from level 0 to level 5. In September 2017, ADS 2.0(Autonomous Drive System : A Vision for Safety 2.0) was released, a safety guideline for development/verification of autonomous driving technology in the Department of Transportation(DOT) and the National High way Traffic Safety Administration(NHTSA). And guidelines suggest 12 safety design elements such as System Safety, Vehicle Cyber Security, Fallback, etc. Meanwhile, the Ministry of land in South Korea, Infrastructure and Transport is pushing for safety verification of autonomous driving commercialization in January 2020 by establishing safety standards for three step of Conditional Automation or Limited Autonomous Driving Automation[5].

Looking at this research trend for safety evaluation of autonomous driving, Christopher et al. conducted a study on generating abstract simulation scenarios for verification of autonomous vehicles [6], Mansur et al. proposed an accelerated approach for testing considering the safety and efficiency of autonomous vehicles on public roads [7]. Tim et al. proposed an open-source graphical user interface for generating multi-vehicle scenarios [8]. Lima et al. discussed global scenarios for self-driving cars focused on new test track proposals, Brazilian transportation systems and certification and approval processes [9]. Galen et al. conducted a study on the automatic generation of various and challenging scenarios for testing and evaluating of self-driving cars [10], and Chai et al. proposed a basic simulation environment for dynamic scenarios of Connected and Autonomous Vehicle [11]. Stark et al. conducted a study on the generation of verification scenarios for autonomous vehicles [12], and Park et al. studied approaches to generating multievent-based simulation scenarios for sensors and devices in autonomous vehicles [13], and Whlschke et al. conducted a study with the aim of deriving test cases [14]. Nabhan et al. conducted a study on scenario range optimization for driving scenarios for autonomous vehicles in simulations [15], and Wen et al. conducted a study on the performance analysis of NDT-based Graph SLAM for autonomous vehicles based on various driving scenarios in Hong Kong [16]. Zheng et al. conducted research on optimization model proposals, simulation tests, and rapid generation of difficult scenarios based on safety, softness, clarity, and smartness to evaluate the autonomy of autonomous vehicle [17], and Wang et al. reviewed automation levels according to the role of automation systems in the selfdriving process, and statistically analyzed autonomous vehicle accidents on public roads [18]. Tuncail et al. studied how to automatically identify simulation-based test scenarios for self-driving cars using machine learning components [19], and Huang et al. conducted a study on the synthesis of test approaches for various autonomous vehicles. [20], Reitz et al. provided a case study on repeated tests and evaluation conducted for many years to support the development of autonomous vehicle systems [21].

Until recently, the research trends are most simulationbased autonomous vehicle evaluation and scenario generation. And study on test case derivation and sensor and device development. Study on safety evaluation theory and autonomous vehicle evaluation method based on actual vehicle test is insufficient. Therefore, in this study, propose a longitudinal relative distance theoretical formula for evaluating the safety of autonomous vehicle and an integrated evaluation scenario for fixed target, and propose a theoretical evaluation method for autonomous vehicle by comparing and verifying them with actual vehicle test.

\section{Test evaluation method}

\subsection{Relative distance theory formula}

In a previous study, the Adaptive Cruise Control(ACC) and AEB systems' evaluation criteria were proposed as target distance values and verified[22, 23]. The explanation is as follows.

The target distance theory formula for ACC is proposed using vehicle speed and distance information measured using Radar sensors to control the speed and distance and the deceleration\&acceleration required for the Stop\&Go function. 
$\mathrm{d}_{\mathrm{des}}=\frac{1}{2}\left[\begin{array}{c}\left(d+d_{0}\right)-\frac{1}{k_{1}}\left(a_{d e s}+k_{2} v_{s}\right) \\ +v_{f}\left(\tau-\frac{k_{2}}{k_{1}}\right)\end{array}\right]$

Where, $\mathrm{d}_{\mathrm{des}}$ is target relative distance, $d_{0}$ is the distance between cars at stop, $\tau$ is the time difference, $v_{f}$ is the speed of the target vehicle, $a_{\text {des }}$ is the target acceleration, $k_{1}, k_{2}$ is the gain, $v_{s}$ is the speed of the control vehicle

AEB is generally controlled by Time to Collision(TTC). Assuming that Enhanced Time to Collision(ETTC), Which strengthened TTC, is equivalent to TTC, proposed AEB's target distance theory formula.

$\mathrm{d}_{\mathrm{vehicle}}=\left(\frac{-\mathrm{TTC}\left(\mathrm{a}_{\mathrm{TV}}-\mathrm{a}_{\mathrm{SV}}\right)+\left(\mathrm{v}_{\mathrm{TV}}-\mathrm{v}_{\mathrm{SV}}\right)^{2}}{2\left(\mathrm{a}_{\mathrm{TV}}-\mathrm{a}_{\mathrm{SV}}\right)}+\right.$
$\left.\frac{\left(\mathrm{a}_{\mathrm{TV}}-\mathrm{a}_{\mathrm{SV}}\right)\left(\mathrm{v}_{\mathrm{TV}}-\mathrm{v}_{\mathrm{SV}}\right)^{2}}{2\left(\mathrm{a}_{\mathrm{TV}}-\mathrm{a}_{\mathrm{SV}}\right)}\right)$

Where, TTC is time to collision, $\mathrm{a}_{\mathrm{TV}}, \mathrm{a}_{\mathrm{SV}}$ is acceleration of fixed target vehicles and autonomous vehicles, $\mathrm{v}_{\mathrm{TV}}$, $\mathrm{v}_{\mathrm{SV}}$ is average velocity of fixed target and autonomous vehicles, $d_{\text {vehicle }}$ is relative distance

Therefore, by combined equations (1) and (2), propose a safety evaluation theoretical formula using the relative longitudinal distance of autonomous vehicles as shown in equation (3).

$\mathrm{d}_{\mathrm{vehicle}}=\left[\begin{array}{l}1 \\ 0\end{array}\right] \frac{1}{2}\left[d_{0}+\left(a_{s v}-v_{s v}\right)+v_{t v}(\tau-1)\right.$

$+\left[\begin{array}{l}1 \\ 0\end{array}\right] \frac{-\left(T T C A_{\text {relative }}\right)^{2}+V_{\text {relative }}^{2}}{2 A_{\text {realtive }}}$

Where, $A_{\text {relative }}$ is $\mathrm{a}_{\mathrm{TV}}-\mathrm{a}_{\mathrm{SV}}, \mathrm{V}_{\text {relative }}$ is $\mathrm{v}_{\mathrm{TV}}-\mathrm{v}_{\mathrm{SV}}$

$\frac{1}{2}\left[d_{0}+\left(a_{s v}-v_{s v}\right)+v_{t v}(\tau-1)\right.$ is a formula that is identifies relative longitudinal distances when the autonomous vehicle follows the lead vehicle. And $\frac{-\left(\text { TTC } A_{\text {relative }}\right)^{2}+V_{\text {relative }}^{2}}{2 A_{\text {realtive }}}$ is a formula that can identify relative distances to obstacles in front of them when braking.

\subsection{Test Scenario}

A scenario for the fixed target of autonomous vehicle proposed as follows.

Fig. 1 is a scenario in which autonomous vehicles can see the response to a fixed target. It was configured of integrated by an own lane following scenario, an emergency braking malfunction evaluation scenario, a crossroad(intersection) scenario(left turn, right turn), a braking \& avoidance scenario, a lane change scenario, a sign recognition scenario.

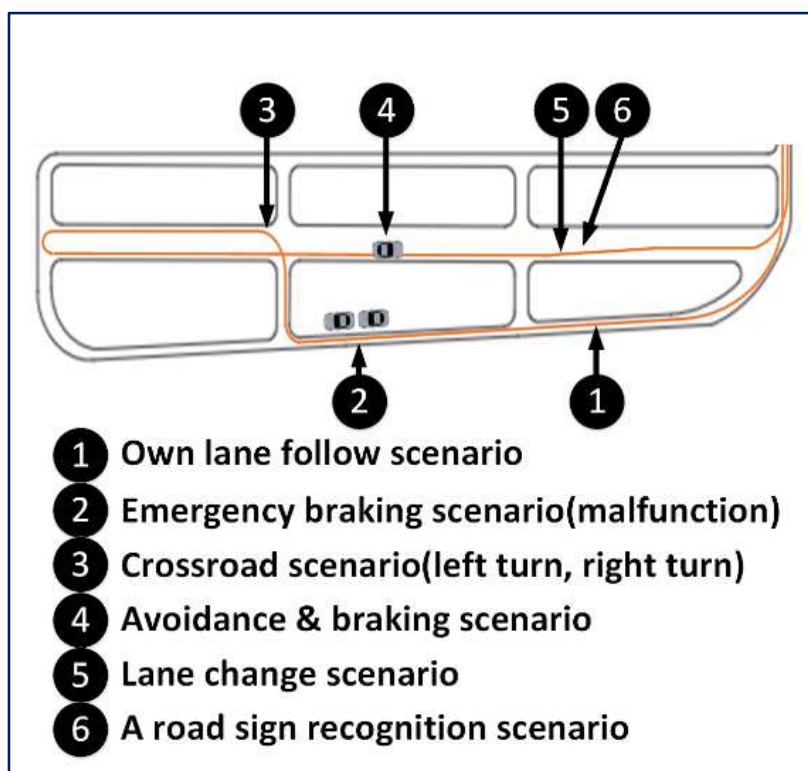

Figure 1 Fixed target scenario for autonomous vehicles.

The maximum speed of the fixed targets scenario was set equally to $40 \mathrm{~km} / \mathrm{h}$, the actual test limit speed for an autonomous vehicle made by company such as Google. The scenario was configured to proceed continuously.

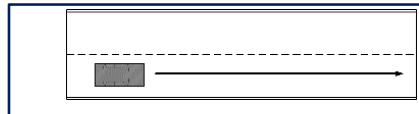

(a)

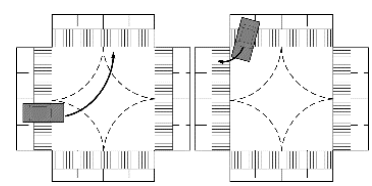

(c)

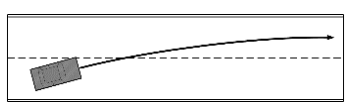

(e)

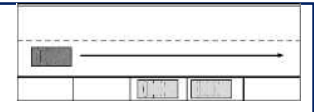

(b)

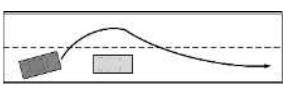

(d)

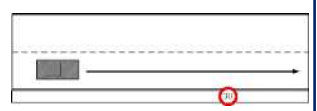

(f)

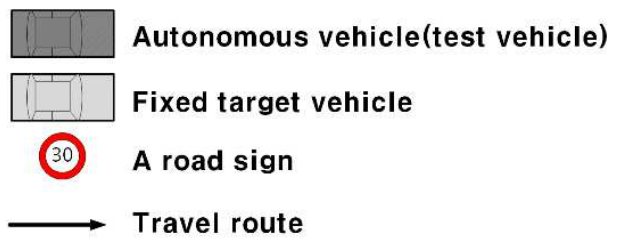

(g)

Figure 2 Scenario for autonomous vehicles

(a) own lane follow scenario (b) emergency braking

scenario(malfunction) (c) crossroad scenario(left turn, right turn) (d) avoidance \& braking scenario (e) lane change scenario (f) a road sign recognition scenario $(\mathrm{g})$ legend

Fig. 2 shows each of the fixed target scenarios in detail. Fig. 2(a) is the own lane follow scenario, and should 
proceed on straight and curved roads, respectively. Fig. 2(b) is the emergency braking malfunction evaluation scenario, recognizes a vehicle stopped(parked) in the side lane and determines whether it is malfunctioning. Fig. 2(c) is a crossroad(intersection) scenario(left turn, right turn) and a scenario in which a signal is read and safely passed. Fig. 2(d) is a braking \& avoidance scenario in which an obstacle is recognized at a certain distance and then slowed down to avoid or stop, rather than emergency braking. Fig. 2(e) is a lane change scenario in which a lane is changed through a set path on a straight road. Fig 2(f) is a road sign recognition scenario. IT constructed and proposed that a $30 \mathrm{~km} / \mathrm{h}$ sign is recognized and deceleration from driving speed of $40 \mathrm{~km} / \mathrm{h}$ to a speed limit of sign.

\section{Actual vehicle test}

\subsection{Actual vehicle test vehicle}

In this study, the actual vehicle test was validated using the proposed longitudinal distance equation and the fixed target evaluation scenario. There are a total of 3 vehicles used in the test, as in Fig. 3 (a) the Avante ADbased autonomous vehicle of $\mathrm{H}$ company, and fixed targets are shown in Fig. 3(b) using IONIQ of H company and QM6 of R company.

The specifications of the autonomous vehicle are shown in Table 1, and the specifications of vehicles used as fixed targets are shown in Table 2

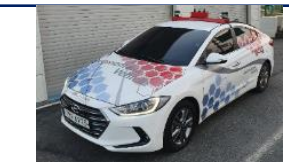

(a)

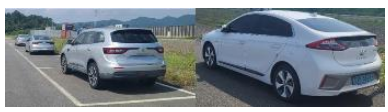

(b)
Figure 3 Test vehicles

(a) autonomous vehicle, (b) fixed target vehicle

Table 1. Autonomous vehicle spec.

\begin{tabular}{ll}
\hline Name & Spec. \\
\hline
\end{tabular}

Table 2. Test device spec.

\begin{tabular}{cl}
\hline Name & \multicolumn{1}{c}{ Spec. } \\
\hline & - 120Ah \\
& - overall length : 4,470mm \\
IONIQ EV & overall width : $1,820 \mathrm{~mm}$ \\
(fixed target) & - overall height : $1,475 \mathrm{~mm}$ \\
& - wheel base $: 2,700 \mathrm{~mm}$ \\
& - motor maximum power : 100.0Kw \\
& - motor maximum torque : 295.0Nm \\
& - drive type : front wheel drive \\
\hline & - 1.6 dCi \\
& - overall length : 4,675mm \\
& - overall width : $1,845 \mathrm{~mm}$ \\
QM 6 & - overall height : $1,670 \mathrm{~mm}$ \\
& - wheel base : $2,705 \mathrm{~mm}$ \\
& - displacement volume : $1,997 \mathrm{cc}$ \\
& - drive type : four wheel drive
\end{tabular}

The autonomous vehicle used in the actual vehicle test is shown in Fig. 4 of sensors such as DGPS, camera, lidar, actuator, and CAN communication equipment, and specifications are shown in Table 3.

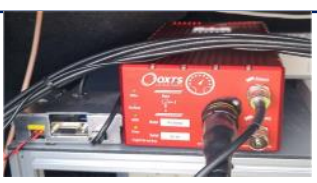

(a)

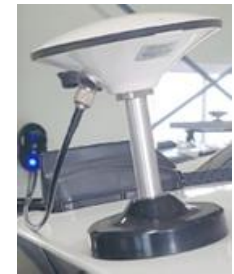

(c)

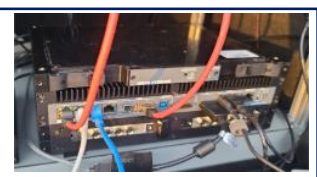

(b)

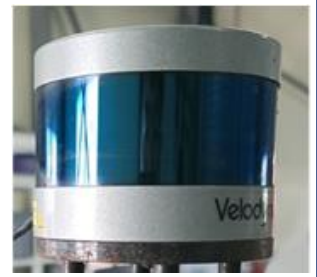

(d)

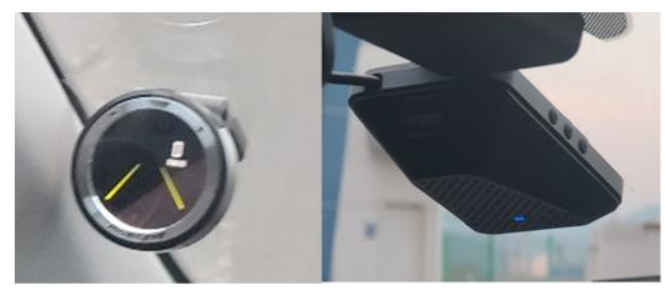

(e)

Figure 4 Test device

(a) RT-3002, (b) Brick, (c) GPS, (d) Radar (e) Camera
$-1.6 \mathrm{GDI}$

- overall length : $4,570 \mathrm{~mm}$

Avante AD - overall width : $1,800 \mathrm{~mm}$

(autonomous - overall height : $1,440 \mathrm{~mm}$

Vehicle) - wheel base : $2,700 \mathrm{~mm}$

- displacement volume : $1,591 \mathrm{cc}$

- drive type : front wheel drive 
Table 3. Test device spec.

\begin{tabular}{|c|c|}
\hline Name & Spec. \\
\hline $\begin{array}{c}\text { RT-3002 } \\
\text { (DGPS) }\end{array}$ & $\begin{array}{l}\text { - single antenna model } \\
\text { - velocity accuracy: } 0.05 \mathrm{~km} / \mathrm{h} \text { RMS } \\
\text { - roll, pitch: } 0.03 \mathrm{deg} \text {, heading } 0.1 \mathrm{deg} \\
\text { - GPS accuracy: } 2 \mathrm{~cm} \text { RMS }\end{array}$ \\
\hline $\begin{array}{l}\text { GNSS } \\
\text { RTK } \\
\text { Antenna } \\
\text { (GPS) }\end{array}$ & $\begin{array}{l}\text { - Frequency Range : GPSL1,L2 /GLONASS } \\
\text { G1,G2/BEIDOU B1,B2,B3 } \\
\text { - Housing RF Connector : TNC K } \\
\text { - Frequency Gain : }>38 \mathrm{~dB} \\
\text { - Housing Diameter : } 150 \mathrm{~mm} \\
\text { - Impedance : } 50 \text { Ohm (Nominal) } \\
\text { - Environment temperature : Operating } \\
\text { temperature: }-45^{\circ} \mathrm{C} \sim 70^{\circ} \mathrm{C}\end{array}$ \\
\hline $\begin{array}{c}\text { Brick } \\
\text { (DAQ) }\end{array}$ & $\begin{array}{l}\text { - Obtain high-bandwidth sensor data } \\
\text { (1 GByte/sec, } 16 \mathrm{~TB} \text { or higher) } \\
\text { - Integrity data can be stored } \\
\text { (ECU sensor/camera } \rightarrow \text { recording file) }\end{array}$ \\
\hline $\begin{array}{l}\text { Lidar } \\
\text { (sensor) }\end{array}$ & $\begin{array}{l}\text { - } 100 \mathrm{~m} \text { range with compact form factor } \\
\text { - Proven } 905 \mathrm{~nm} \text { tech, with largest install base } \\
\text { - Top-of-the-line field-of-view } \\
\text { - Best-in-class accuracy and calibrated } \\
\text { intensity } \\
\text { - Best-in-class power and temperature range } \\
\text { - Sensor-to-sensor interference mitigation } \\
\text { feature } \\
\text { - Optional, enhanced short range detection }\end{array}$ \\
\hline $\begin{array}{l}\text { Camera } \\
\text { (sensor) }\end{array}$ & $\begin{array}{l}\text { - Vision Sensor: Aptina MT9V024 (1/3") RCC } \\
\text { - Array Format: Total: } 752 \mathrm{H} \text { x } 480 \mathrm{~V} \text { - Active } \\
\text { pixels: } 640 \mathrm{H} \text { x } 480 \mathrm{~V} \\
\text { - Optical Format: } 1 / 3 " \\
\text { - Pixel Size: } 6.0 \mu \mathrm{m} \text { x } 6.0 \mu \mathrm{m} \\
\text { - Dynamic Range: >55dB linear; } \\
\text { >100dB in HDR mode } \\
\text { - Shutter type: Global shutter - TrueSNAPTM } \\
\text { - Responsivity: } 4.8 \mathrm{~V} / \text { lux sec }(550 \mathrm{~nm}) \\
\text { - Angle of view: } 38^{\circ} \text { (horizontal) } \\
\text { - Focus range: } 5 \mathrm{~m} \text { to infinity } \\
\text { - AGC: Automatic Gain Control of the image } \\
\text { sensor for high dynamic range }\end{array}$ \\
\hline
\end{tabular}

\subsection{Actual vehicle test location}

The actual vehicle test was shown in Fig. 5 by utilizing the vehicle-road connection test intersection during the driving test of the KIAPI(Korea Intelligent Automotive Parts Promotion Institute). The driving test road used STANLEY LONDON's 'skid-resistance' to determine that the mean friction coefficient on the road surface was 1.08. And the actual road friction coefficient, road width, etc. were applied, so it was judged suitable for the test site.

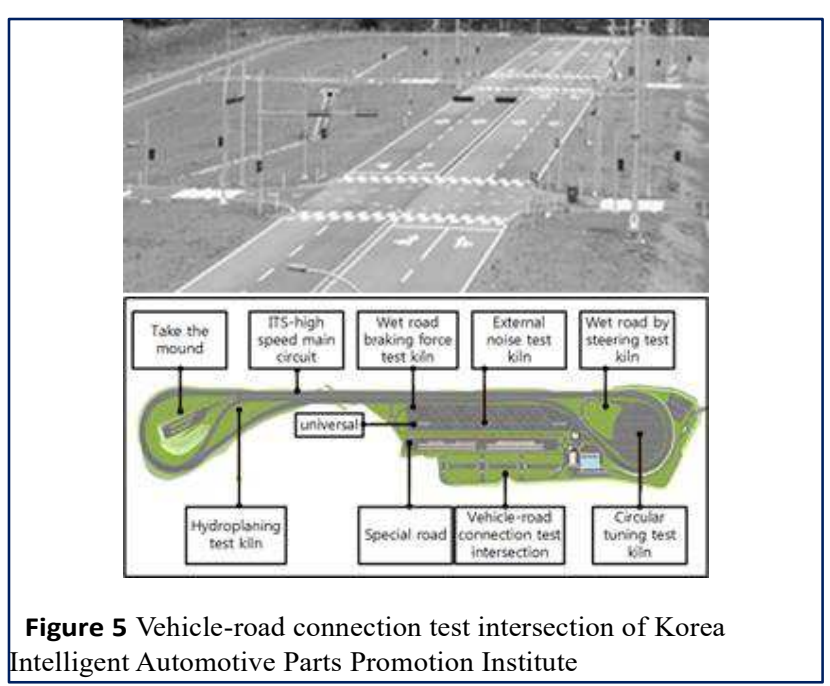

\subsection{Actual vehicle test conditions}

For objective data acquisition, test scenarios must be reproduced equally repeatedly. Accordingly, the number of people conducting the actual test and the test equipment and control coding remained the same and were repeated three times under the same environmental conditions.

The test environment conditions listed in Table 4 were carried out, and there were no changes in the weather, such as showers.

Table 4. Environmental condition

\begin{tabular}{cc}
\hline Item & Spec. \\
\hline Road condition & - flat, dry and clean asphalt or concrete \\
\hline Temperature $\left({ }^{\circ} \mathrm{C}\right)$ & $-18.3-30.4$ \\
\hline Wind speed $(\mathrm{m} / \mathrm{s})$ & -1.9 \\
\hline Weather & - sunny \\
\hline
\end{tabular}

\section{Comparative analysis of test results}

\subsection{Actual vehicle test results}

The actual vehicle test results are shown in Fig. 6 9. Based on the proposed fixed target scenario, four types of actual vehicle test scenario were each repeated three times. 


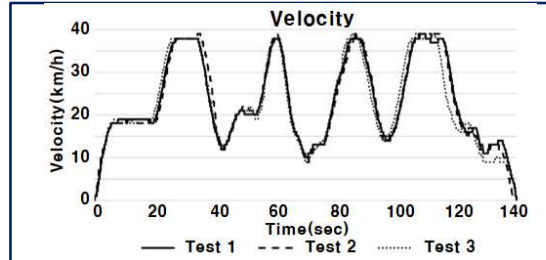

(a)

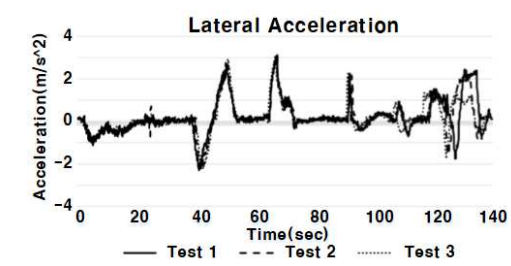

(d)

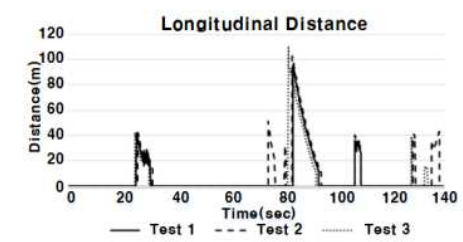

(g)

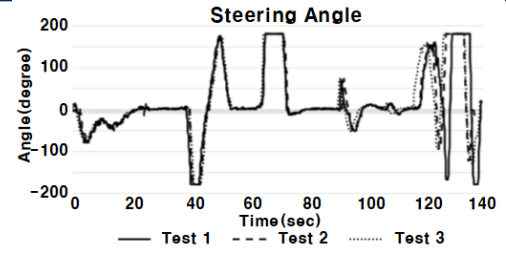

(b)

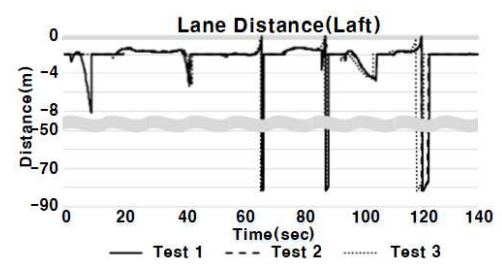

(e)

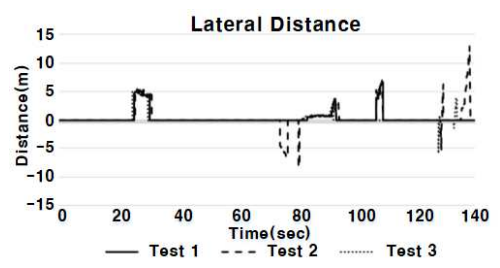

(h)

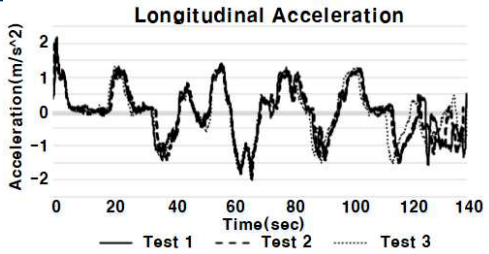

(c)

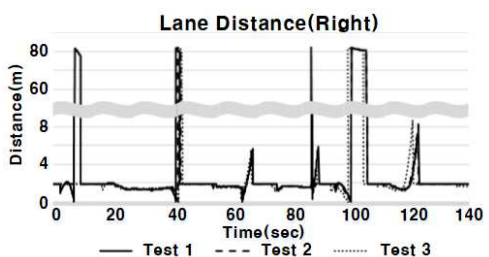

(f)

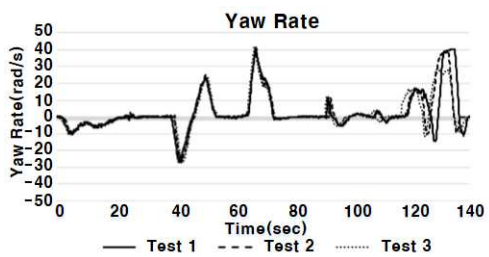

(i)

Figure 6 Test results(First Test Form)

(a) speed, (b) steering angle (c) longitudinal acceleration (d) lateral acceleration (e) left lane distance (f) right lane distance (g) longitudinal relative distance $(\mathrm{h})$ lateral relative distance (i) yaw rate

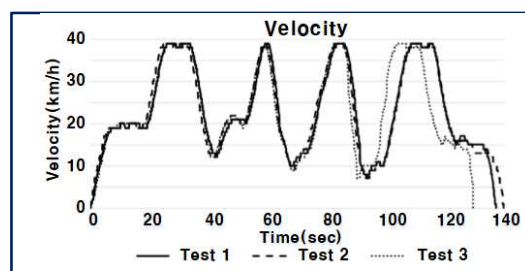

(a)

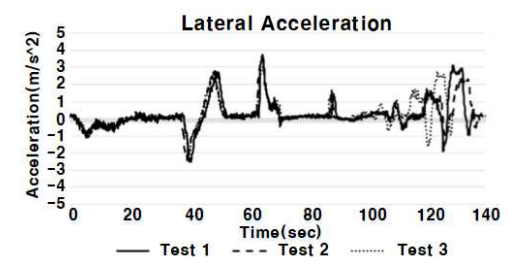

(d)

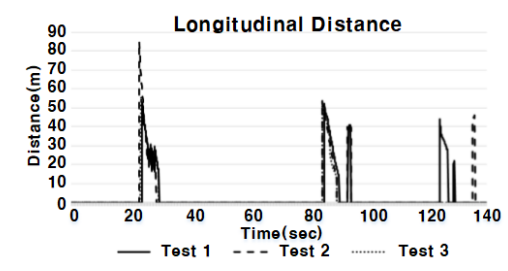

(g)

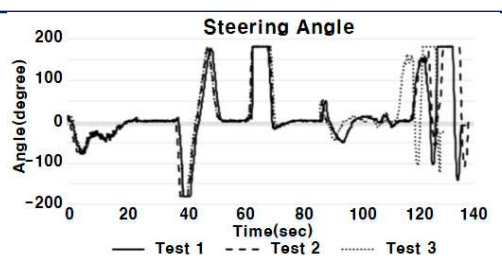

(b)

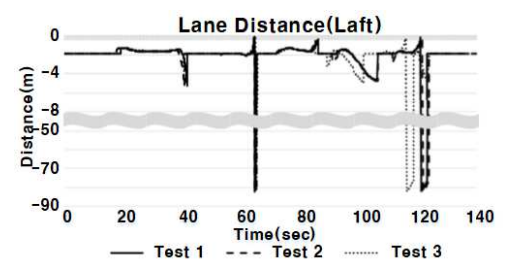

(e)

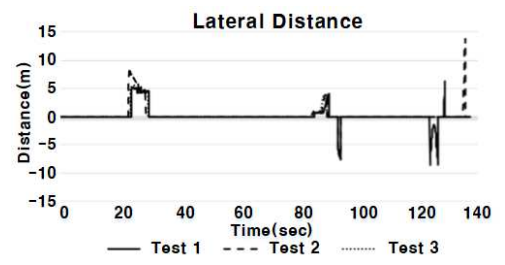

(h)

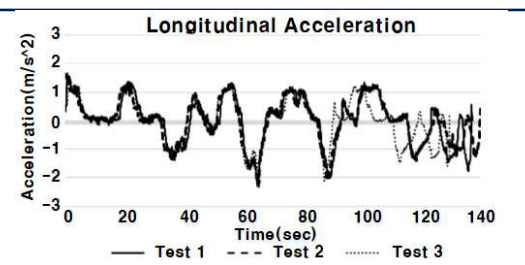

(c)

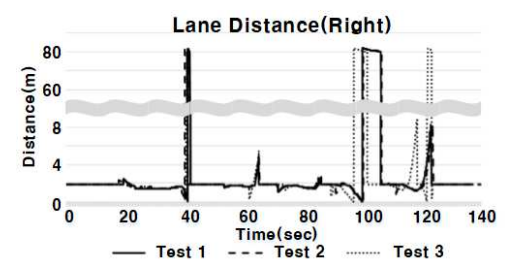

(f)

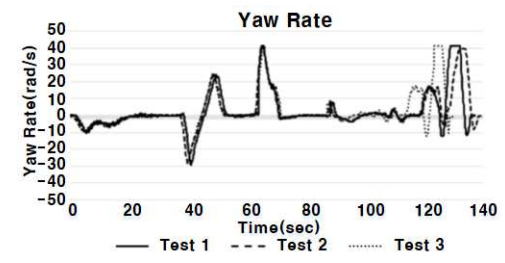

(i)

Figure 7 Test results(Second Test Form)

(a) speed, (b) steering angle (c) longitudinal acceleration (d) lateral acceleration (e) left lane distance (f) right lane distance (g) longitudinal relative distance $(\mathrm{h})$ lateral relative distance (i) yaw rate 


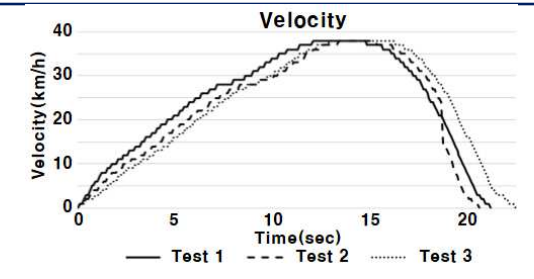

(a)

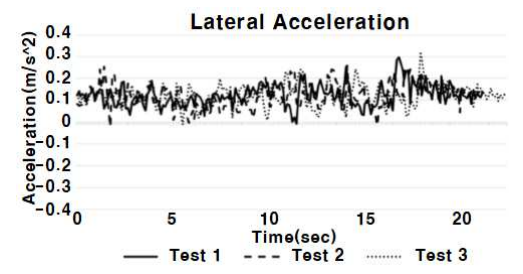

(d)

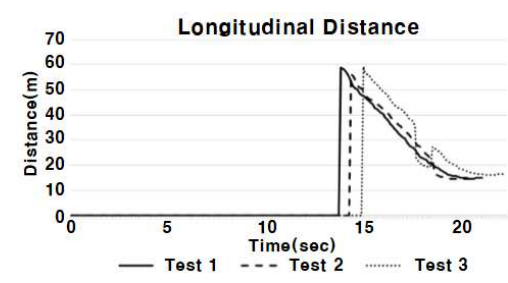

(g)

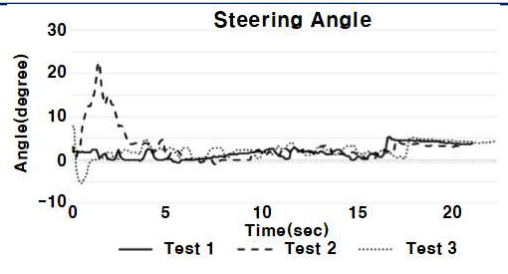

(b)

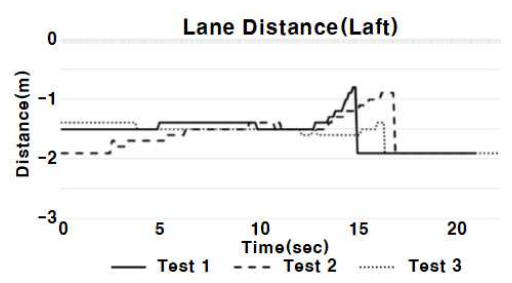

(e)

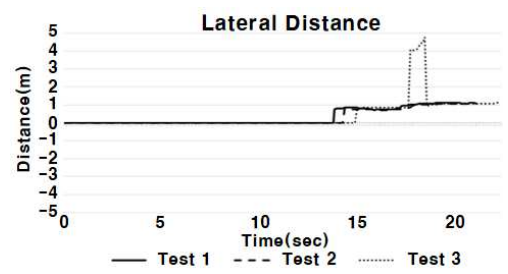

(h)

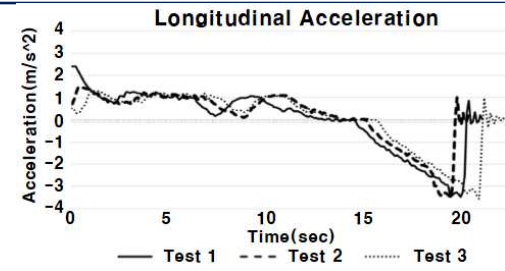

(c)

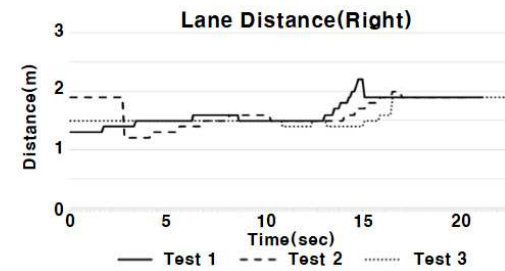

(f)

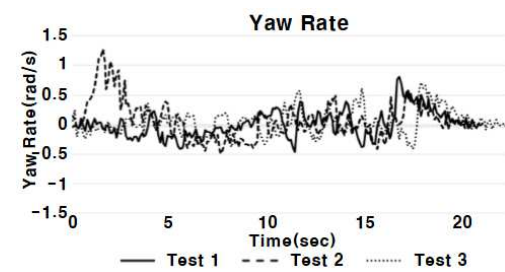

(i)

Figure 8 Test results(Third Test Form)

(a) speed, (b) steering angle (c) longitudinal acceleration (d) lateral acceleration (e) left lane distance (f) right lane distance (g) longitudinal relative distance (h) lateral relative distance (i) yaw rate

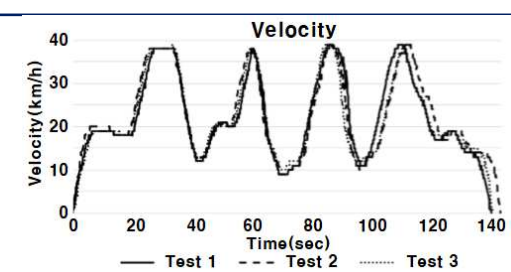

(a)

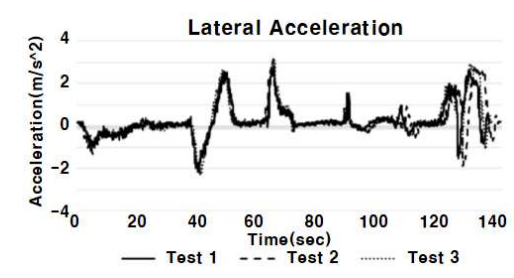

(d)

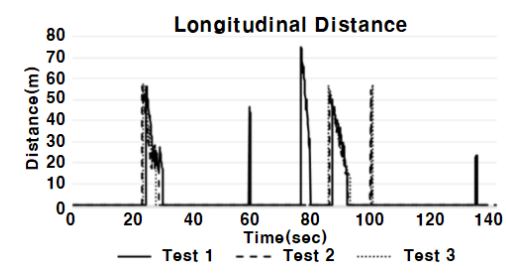

(g)

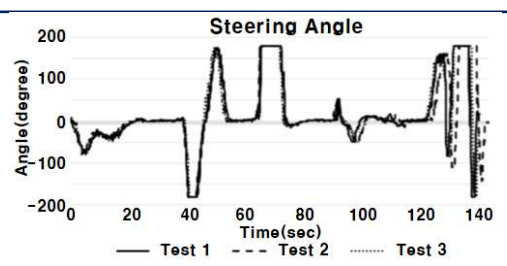

(b)

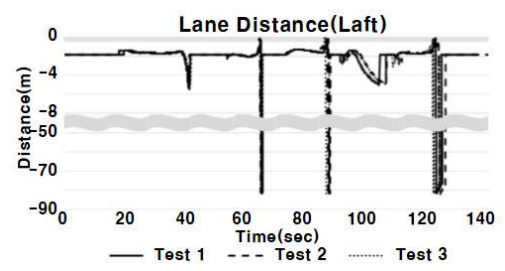

(e)

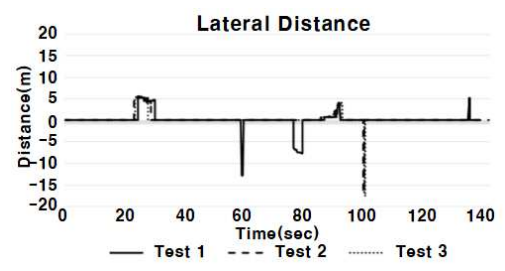

(h)

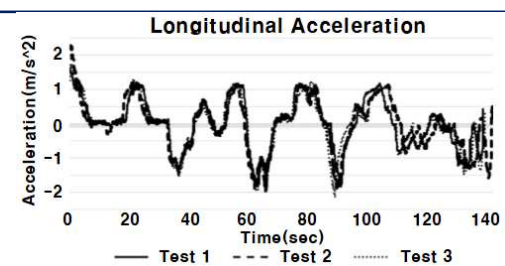

(c)

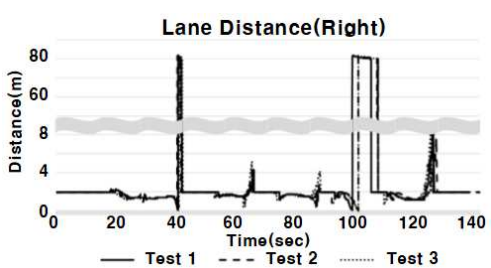

(f)

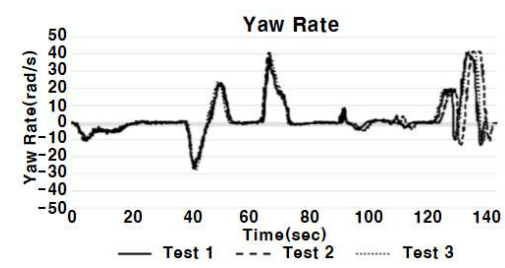

(i)

Figure 9 Test results(Fourth Test Form)

(a) speed, (b) steering angle (c) longitudinal acceleration (d) lateral acceleration (e) left lane distance (f) right lane distance (g) longitudinal relative distance (h) lateral relative distance (i) yaw rate 
The first test was to exclude road sign recognition from the scenario of Fig. 1. And the result is Fig. 6.

Referring to Fig. 6, it can be seen accelerate to an own lane follow the section on about $0-25$ seconds. The about 25-35 seconds section have been identified passes without malfunction as an emergency braking malfunction scenario section. And about 30-45 seconds, the right turn section was decelerated, and the right turn was performed. About 45-55 seconds, the left turn was made to enter the second lane. And about 55-75 seconds, after the left turn was completed the U-turn proceeded. About 75-100 seconds, were after recognizing the fixed target from a distance, it slowed down slowly and returned to the main lane after evading. After acceleration, about 100-115 seconds, the lane change scenario proceeds and decelerate for the end of the scenario. And after about 115 seconds, the scenario was finished.

The second test is to avoid obstacles by braking slower than the first scenario and the result is Fig. 7.

Referring to Fig. 7, it can be seen that the tendency similar to the results of the first test (form) in Fig. 6. But, about 75 to 100 seconds, after the process of recognizing the fixed target, after deceleration and avoidance, it can check difference at returning process to the main lane, in the braking velocity and longitudinal deceleration and avoiding relative distance, etc.

The third test is to recognize and brake a fixed target on straight road, and the results is Fig. 8.

Referring to Fig. 8, about 0-25 seconds, it was accelerated on a straight road after the fixed target was recognized from a distance and then slowly decelerated and braked.

The fourth test is the scenario for Fig. 1, and the result is Fig. 9.

Referring to Fig.9, it can be seen that it has a similar trend to the first test result in Fig. 6. But, due to the difference in the presence or absence of road signs, at between about 110-120 seconds can check the difference in velocity, longitudinal deceleration, avoiding relative distance, etc.

All four tests were repeated three times, and the results of each test were similar. Still the difference was judged due to the difference in time between acceleration at the start of the scenario and the autonomous vehicle's U-turn.
The relative distance at the start of the avoidance of selfdriving cars for fixed targets in the first, second and fourth tests and the actual braking completion relative distance of the third test are organized in Table 5.

Table 5. Relative distance during avoidance among test results

\begin{tabular}{|c|c|c|}
\hline Scenario & & ative distance [m] \\
\hline \multirow{3}{*}{ First Test } & 1 & 12.53 \\
\hline & 2 & 10.90 \\
\hline & 3 & 10.78 \\
\hline \multirow{3}{*}{ Second Test } & 1 & 13.90 \\
\hline & 2 & 13.34 \\
\hline & 3 & 13.21 \\
\hline \multirow{3}{*}{ Third Test } & 1 & 14.65 \\
\hline & 2 & 14.21 \\
\hline & 3 & 16.03 \\
\hline \multirow{3}{*}{ Fourth Test } & 1 & 13.59 \\
\hline & 2 & 13.96 \\
\hline & 3 & 13.59 \\
\hline
\end{tabular}

\subsection{Comparative analysis of theoretical formula} and actual vehicle test results

Table 6 shows the error rate comparing the calculated value for the relative distance when avoiding the fixed target and the actual vehicle test result using the theoretical formula.

The error rate of the actual vehicle test result value compared to the theoretical relative distance at the time of avoidance is $0.5 \%$ in the fixed targets avoidance test in the second of the first test. The avoidance of the fixed target in the second(test) of the fourth test in the test, the maximum error rate was $7.4 \%$.

Table 6. Comparative analysis of results

\begin{tabular}{ccccc}
\hline Scenario & & $\begin{array}{c}\text { Relative } \\
\text { Distance } \\
{[\mathrm{m}]}\end{array}$ & $\begin{array}{c}\text { Theoretical } \\
\text { Distance } \\
{[\mathrm{m}]}\end{array}$ & $\begin{array}{c}\text { Error } \\
\text { rate } \\
{[\%]}\end{array}$ \\
\hline \multirow{2}{*}{$\begin{array}{c}\text { First } \\
\text { Test }\end{array}$} & 1 & 12.53 & 13.34 & 6.5 \\
\cline { 2 - 5 } & 2 & 10.90 & 10.95 & 0.5 \\
\hline \multirow{2}{*}{$\begin{array}{c}\text { Second } \\
\text { Test }\end{array}$} & 1 & 10.78 & 11.23 & 4.2 \\
\cline { 2 - 5 } & 2 & 13.90 & 14.57 & 4.8 \\
\hline \multirow{2}{*}{ Third } & 3 & 13.34 & 12.76 & 4.3 \\
\cline { 2 - 5 } Test & 2 & 14.65 & 12.71 & 3.8 \\
\cline { 2 - 5 } & 3 & 14.21 & 14.05 & 4.1 \\
\hline \multirow{2}{*}{ Fourth } & 1 & 13.59 & 14.45 & 1.7 \\
\cline { 2 - 5 } Test & 2 & 13.96 & 15.43 & 3.7 \\
\cline { 2 - 5 } & 3 & 13.59 & 12.59 & 7.4 \\
\hline
\end{tabular}

Fig. 6, 7, 9's (e), (f) are the distance to the lanes, at the crossroad measurement results was divergence. It was confirmed an error of about $13 \mathrm{~cm}$ with the average distance result to the lane when avoiding (about 3.28m) and the observation lane width (about $3.15 \mathrm{~m}$ ).

Fig. 8's (e) and (f) are the distances to the lane, indicating a change in value at the crossroad. 
The distance to the lane was judged to be diverged because there was no line at the crossroad. And the measurement error was judged by problems such as lane recognition by the camera and lanes reflected by sunlight. It was also judged that the change in the value at the crossroad of the third test without diverging was because the velocity at the time of passing through the crossroad was higher than that of the other(first, second, and fourth) tests.

Fig. 6, 7, 9 of (g), (h) are the relative distance to the longitudinal and lateral obstacles. And except for about 25-35 and about 75-100, other obstacles(such as street lamps) were also recognized and responded. Fig. 6, 7, 9 's (g), (h) are the relative distance to the longitudinal and lateral obstacles. And except for about 25-35 and about 75-100, other obstacles(such as street lamps) were also recognized and responded.

Fig. 8's (g), (h) is the relative distance to the longitudinal and lateral obstacles. The fixed target was recognized, and the braking was confirmed by deceleration. Also, Fig. 8's (c) found that the reason for the large result value compared to other tests with longitudinal deceleration was due to braking, not avoidance.

This error was judged as an error due to sensor recognition due to the scenario progress method, the test path's condition, and the weather such as sunlight, even though the same scenario was performed.

\section{Conclusion}

In this study, a test scenario and a theoretical formula of longitudinal distance for the evaluation of autonomous vehicles for fixed targets were proposed. However, by comparing and analyzing the error rate between the theoretical value and the measured value through the actual vehicle test, it evaluates the applicability of autonomous vehicle of the longitudinal distance theoretical formula for the proposed scenario.

(1) Autonomous vehicle safety assessment scenarios for fixed target are proposed by integrated scenarios such as own lane follow, emergency braking malfunction assessment, crossroad(left turn, right turn), braking \& avoidance, lane change, road sign recognition, etc.

(2) A theoretical evaluation formula of the longitudinal distance of an autonomous vehicle for distance from fixed targets was proposed.

(3) To verify the proposed scenario and the theory formula, the same device was used and repeated tests three times. An autonomous vehicle and a test road of the KIAPI were used.

(4) The scenario test result is compared to the theoretical value. In the second test of the first test scenario, the fixed target's avoidance test in driving own lane, the minimum error rate was $0.5 \%$. In the second test of the fourth test scenario, the fixed target's avoidance test in driving own lane, the maximum error rate was $7.4 \%$.

(5) Looking at the results of the first, second, fourth tests, the distance from the crossroad to the lane was diverged, and the third scenario results was the change in the distance from the crossroad to the lane. he distance to the lane was judged to be diverge because there was no straight lane at the crossroad, and the measurement error was determined to be a problem, such as a camera's lane recognition and sunlight reflection. And it is judged that the value does not diverge and changes at the crossroad of the third test because the velocity at the time of passing through the crossroad was higher than that of other tests. It was confirmed that the relative distance results of the first, second, and fourth tests were reflected in the resulting graph by recognizing other obstacles such as streetlights in addition to the fixed target. The third scenario's relative distance can be seen to have been braking by recognizing the fixed target and slowing it down.

(6) The error of $0.5 \%-7.4 \%$ was the error according to the sensor's recognition, the test method of the scenario, the condition of the test road path, the weather such as sunlight, etc. and it was judged that the reliability of the proposed theory was within $8 \%$.

Therefore, an expensive device such as rider, radar, DGPS, etc, used in the evaluating of autonomous vehicles and the need for experts have a large disadvantage of cost and time burden. But using the proposed theoretical formula, it is possible to grasp the tendency toward the longitudinal direction in the development stage. It is judged that it can be used as a safety evaluation method in an environment where actual vehicle testing is impossible.

In this study, a scenario for a fixed target scenario was proposed through theoretical formulas and actual vehicle tests for safety evaluation of autonomous vehicles and compared and verified them for verification. Testing of Moving Target will be conducted in the future. 


\section{Author contributions}

Conceptualization : S.-B.L., methodology : S.-B.L., actual test : B.-J. K. and S.B.L., data analysis : B.-J. K. and S.-B.L., investigation : B.-J. K., writing-origina draft preparation : B.-J. K. and S.-B.L., writing-review and editing : B.-J. K. and S.-B.L., All authors have read and agreed to the published version of the manuscript.

\section{Declaration of conflicting interests}

The author(s) declared no potential conflicts of interest with respect to the research, authorship, and/or publication of this article.

\section{Funding}

This work was supported by the Technology Innovation Program (10079967, Technical development of demonstration for evaluation of autonomous vehicle system) funded By the Ministry of Trade, Industry \& Energy(MOTIE, Korea)

\section{Acknowledgements}

This work was supported by the Technology Innovation Program (10079967, Technical development of demonstration for evaluation of autonomous vehicle system) funded By the Ministry of Trade, Industry \& Energy(MOTIE, Korea)

\section{Profiles}

Bong-Ju Kim https://orcid.org/0000-0003-3954-1245

Seon-Bong Lee https://sciprofiles.com/profile/112888

\section{Data availability}

The data used to support the findings of this paper are included within the article.

\section{References}

[1] World Health Organization, 'GLOBAL STATUS REPORT ON ROAD SAFETY 2018', 2018

[2] Road Traffic Authority, Traffic Accident Analysis System, 2019, (http://taas.koroad.or.kr/).

[3] K. Mahadevan, S. Somanath, E. Sharlin, "Communicating Awareness and Intent in autonomous Vehicle-Pedestrian Interaction," in Proc. 2018 CHI Conference on Human Factors in Computing Systems, pp. 1-12, 2018.

[4] Byungyong You, Korea Contents Association v.15 no.2, pp. 14- 20, 2017.

[5] SAE, Taxonomy and Definitions for Terms Related to Driving Automation Systems for On-road Motor Vehicles, Standard No.J3016, 2018

[6] C. Medrano-Berumen and M. I. Akbaş, "Abstract Simulation Scenario Generation for Autonomous Vehicle Verification," 2019 SoutheastCon, Huntsville, AL, USA, pp. 1-6, 2019.

doi: 10.1109/SoutheastCon42311.2019.9020575.

[7] M. Arief, P. Glynn and D. Zhao, "An Accelerated Approach to Safely and Efficiently Test Pre-Production Autonomous Vehicles on Public Streets," 2018 21s International Conference on Intelligent Transportation Systems (ITSC), Maui, HI, pp. 2006-2011, 2018 .

doi: 10.1109/ITSC.2018.8569371.

[8] T. Stahl and J. Betz, "An Open-Source Scenario Architect for Autonomous Vehicles," 2020 Fifteenth International Conference on Ecological Vehicles and Renewable Energies (EVER), Monte-Carlo, Monaco, pp. 1-8, 2020. doi: 10.1109/EVER48776.2020.9243029.

[9] Lima, D., Miranda Neto, A., Martinesco, A., Texeira da Silva, S. et al., "Automated Driving Systems and Their Insertion in the Brazilian Scenario: A Test Track Proposal,” SAE Int. J. Trans. Safety, Vol. 6, no.1, pp.1-15, 2018. doi:10.4271/09-06-01-0004.

[10] G. E. Mullins, P. G. Stankiewicz and S. K. Gupta, "Automated generation of diverse and challenging scenarios for test and evaluation of autonomous vehicles," 2017 IEEE International Conference on Robotics and Automation (ICRA), Singapore, pp. 1443-1450, 2017.

doi: 10.1109/ICRA.2017.7989173.

[11] Chai L, Cai B, ShangGuan W, Wang J, Wang H. Basic Simulation

Environment for Highly Customized Connected and Autonomous Vehicle

Kinematic Scenarios. Sensors. Vol. 17, no.9, 1938, 2017.

doi: https://doi.org/10.3390/s17091938

[12] C. Stark, C. Medrano-Berumen and M. İ. Akbaş, "Generation of Autonomous Vehicle Validation Scenarios Using Crash Data," 2020 SoutheastCon, Raleigh, NC, USA, pp. 1-6, 2020

doi: 10.1109/SoutheastCon44009.2020.9249662

[13] Park J, Wen M, Sung Y, Cho K. Multiple Event-Based Simulation Scenario

Generation Approach for Autonomous Vehicle Smart Sensors and Devices.

Sensors, Vol. 19, no.20, 4456, 2019.

doi: https://doi.org/10.3390/s19204456
[14] C. Wolschke, T. Kuhn, D. Rombach and P. Liggesmeyer, "Observation Based Creation of Minimal Test Suites for Autonomous Vehicles," 2017 IEEE International Symposium on Software Reliability Engineering Workshops (ISSREW), Toulouse, pp. 294-301, 2017. doi: 10.1109/ISSREW.2017.46.

[15] M. Nabhan, M. Schoenauer, Y. Tourbier and H. Hage, "Optimizing coverage of simulated driving scenarios for the autonomous vehicle," 2019 IEEE International Conference on Connected Vehicles and Expo (ICCVE), Graz, Austria, pp. 1-5, 2019.

doi: 10.1109/ICCVE45908.2019.8965211.

[16] Wen W, Hsu L-T, Zhang G. Performance Analysis of NDT-based Graph SLAM for Autonomous Vehicle in Diverse Typical Driving Scenarios of Hong Kong. Sensors. Vol. 18, no. 11, 3928, 2018.

doi: https://doi.org/10.3390/s18113928

[17] X. Zheng, H. Liang, B. Yu, B. Li, S. Wang and Z. Chen, "Rapid Generation of Challenging Simulation Scenarios for Autonomous Vehicles Based on Adversarial Test," 2020 IEEE International Conference on Mechatronics and Automation (ICMA), Beijing, China, pp. 1166-1172, 2020 doi: 10.1109/ICMA49215.2020.9233535.

[18] Jun Wang, Li Zhang, Yanjun Huang, and Jian Zhao, "Safety of Autonomous Vehicles", Journal of Advanced Transportation, Vol. 2020, 2020. doi: https://doi.org/10.1155/2020/8867757

[19] C. E. Tuncali, G. Fainekos, H. Ito and J. Kapinski, "Simulation-based Adversarial Test Generation for Autonomous Vehicles with Machine Learning Components," 2018 IEEE Intelligent Vehicles Symposium (IV), Changshu, pp. $1555-1562,2018$. doi: 10.1109/IVS.2018.8500421

[20] Z. Huang, M. Arief, H. Lam and D. Zhao, "Synthesis of Different Autonomous Vehicles Test Approaches," 2018 21st International Conference on Intelligent Transportation Systems (ITSC), Maui, HI, pp. 2000-2005, 2018 doi: 10.1109/ITSC.2018.8569672.

[21] B. C. Reitz and J. L. Wilkerson, "Test and Evaluation of Autonomous Surface Vehicles: A Case Study," 2020 IEEE/ION Position, Location and Navigation Symposium (PLANS), Portland, OR, USA, pp. 839-850, 2020. doi: 10.1109/PLANS46316.2020.9110129.

[22] B. J. Kim, and S. B. Lee, "A Study on Evaluation Method of ACC Test Considering Domestic Road Environment", Journal of Korean Auto-Vehicle Safety Association, Vol. 9, no.4, pp.38-47, 2017.

[23] B. J. Kim, and S. B. Lee, "A Study on Evaluation Method of AEB Test", Journal of Korean Auto-Vehicle Safety Association, Vol. 10, no.2, pp.20-28, 2018. 
Figures

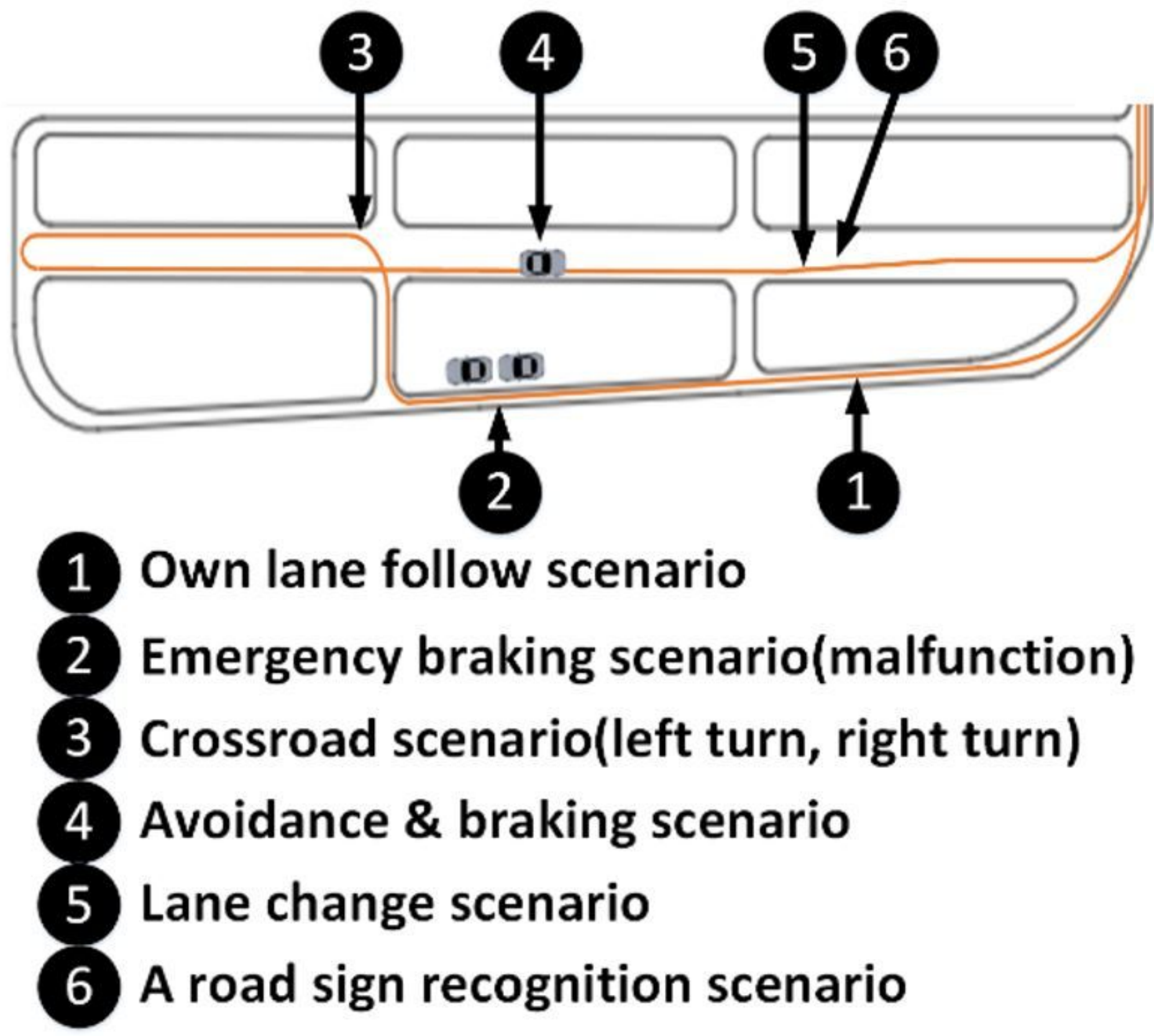

Figure 1

Fixed target scenario for autonomous vehicles. 


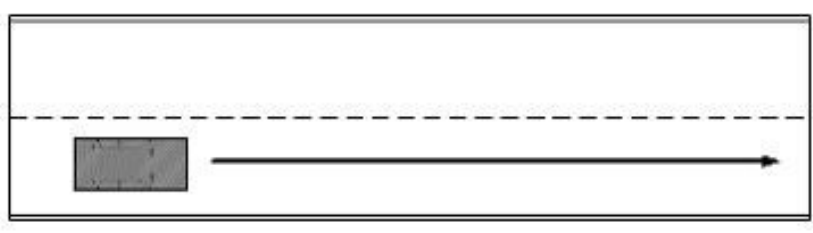

(a)

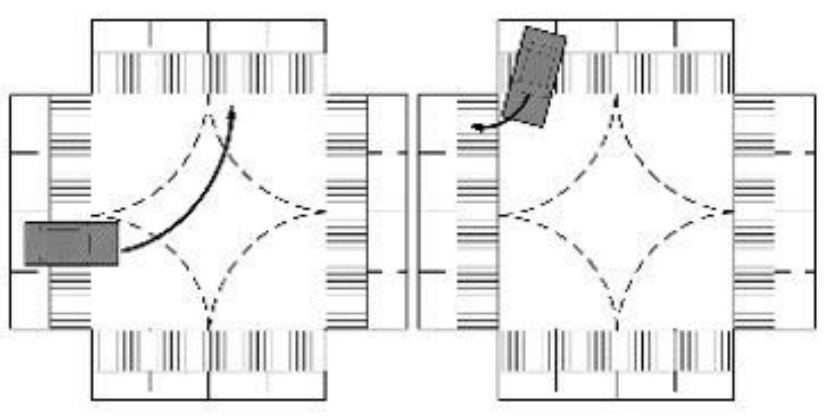

(c)

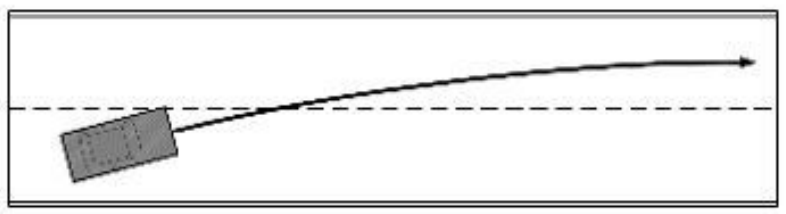

(e)

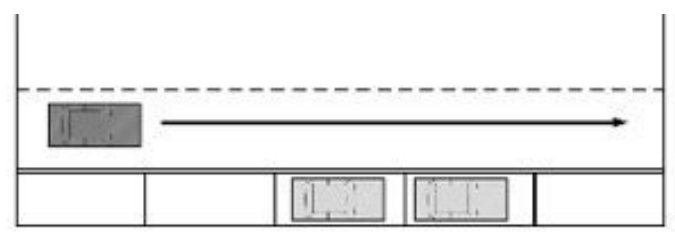

(b)

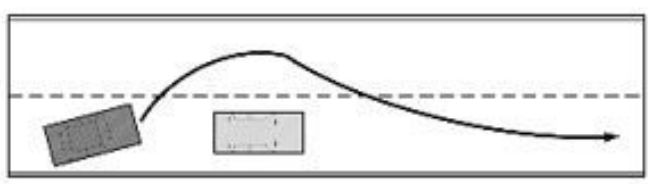

(d)

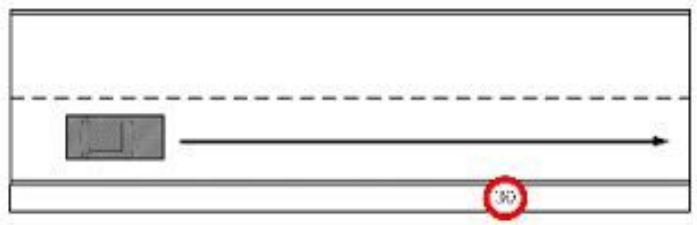

(f)

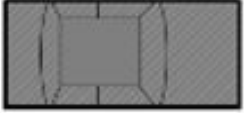

\section{Autonomous vehicle(test vehicle)}

Fixed target vehicle

(30) A road sign

Travel route

(g)

Figure 2

Scenario for autonomous vehicles (a) own lane follow scenario (b) emergency braking scenario(malfunction) (c) crossroad scenario(left turn, right turn) (d) avoidance \& braking scenario (e) lane change scenario $(\mathrm{f})$ a road sign recognition scenario $(\mathrm{g})$ legend 

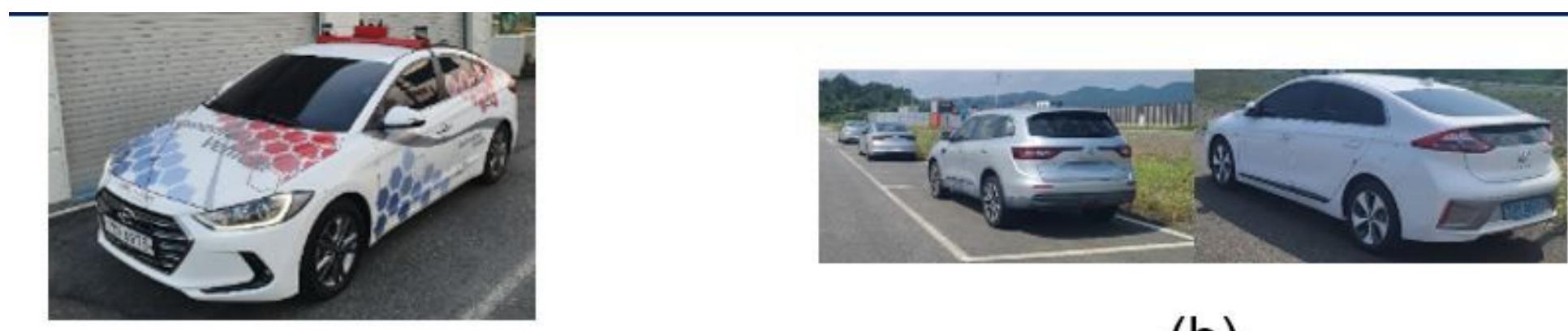

(a)

(b)

Figure 3

Test vehicles (a) autonomous vehicle, (b) fixed target vehicle 




(a)



(c)

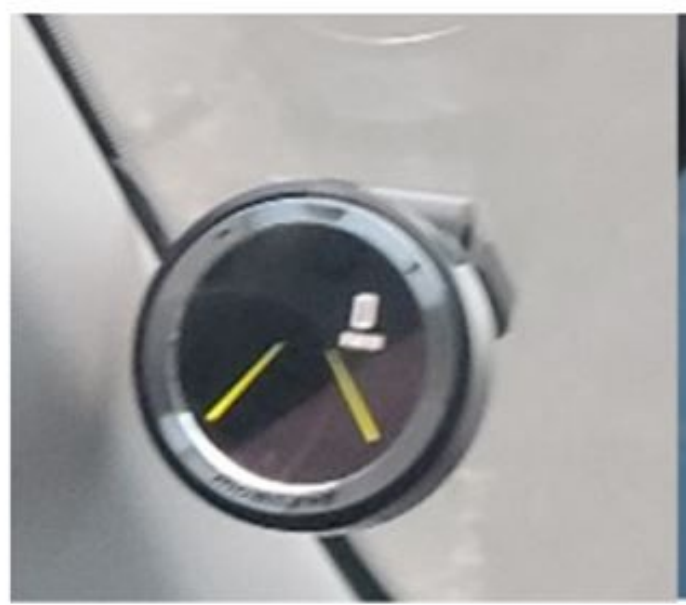

\section{(e)}

Figure 4

Test device (a) RT-3002, (b) Brick, (c) GPS, (d) Radar (e) Camera

(b)

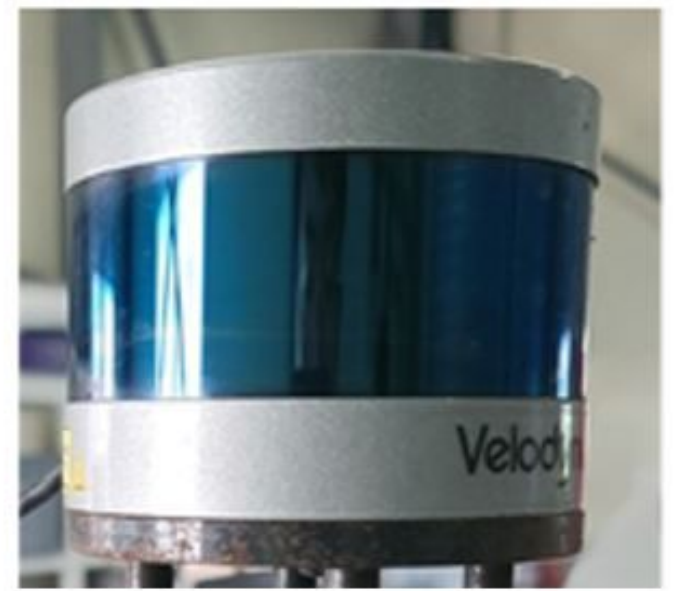

(d)
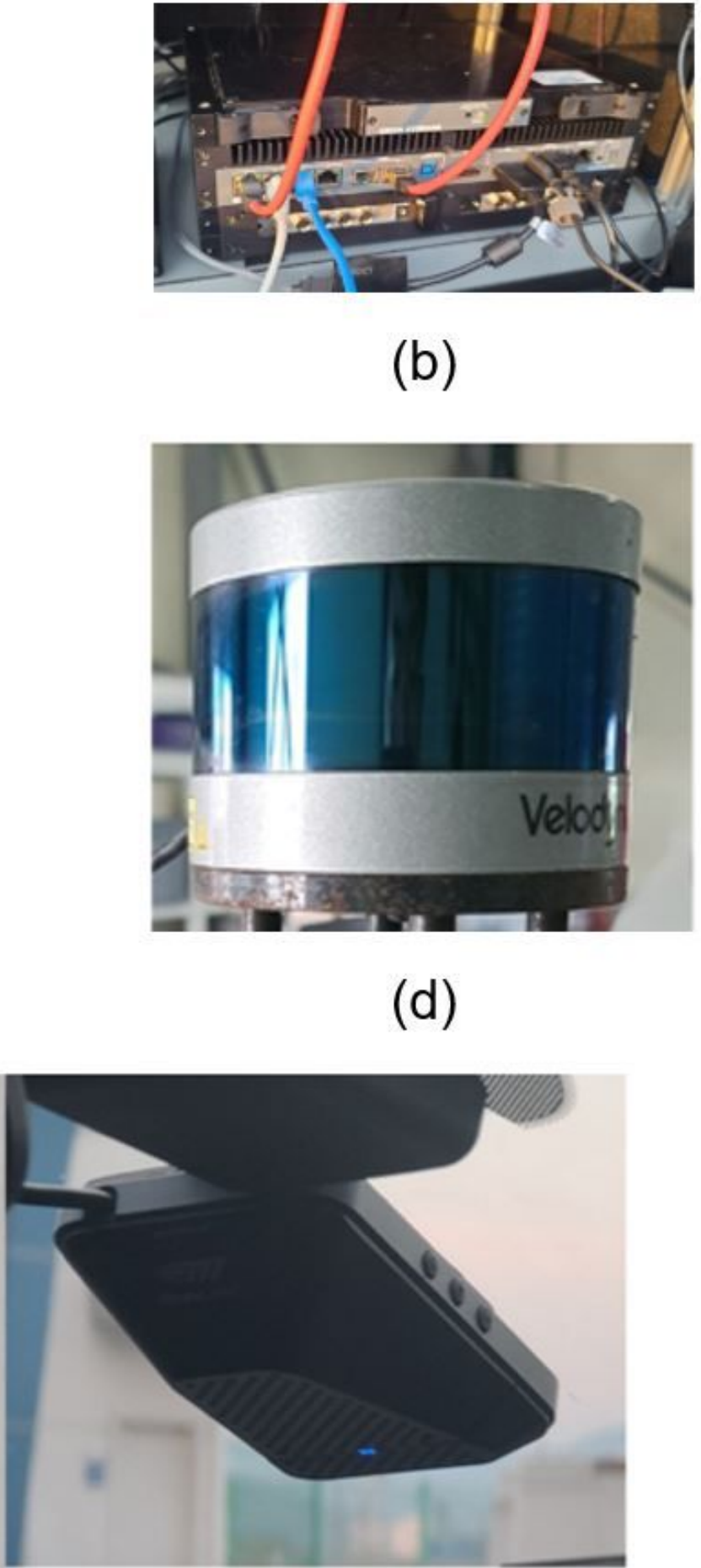

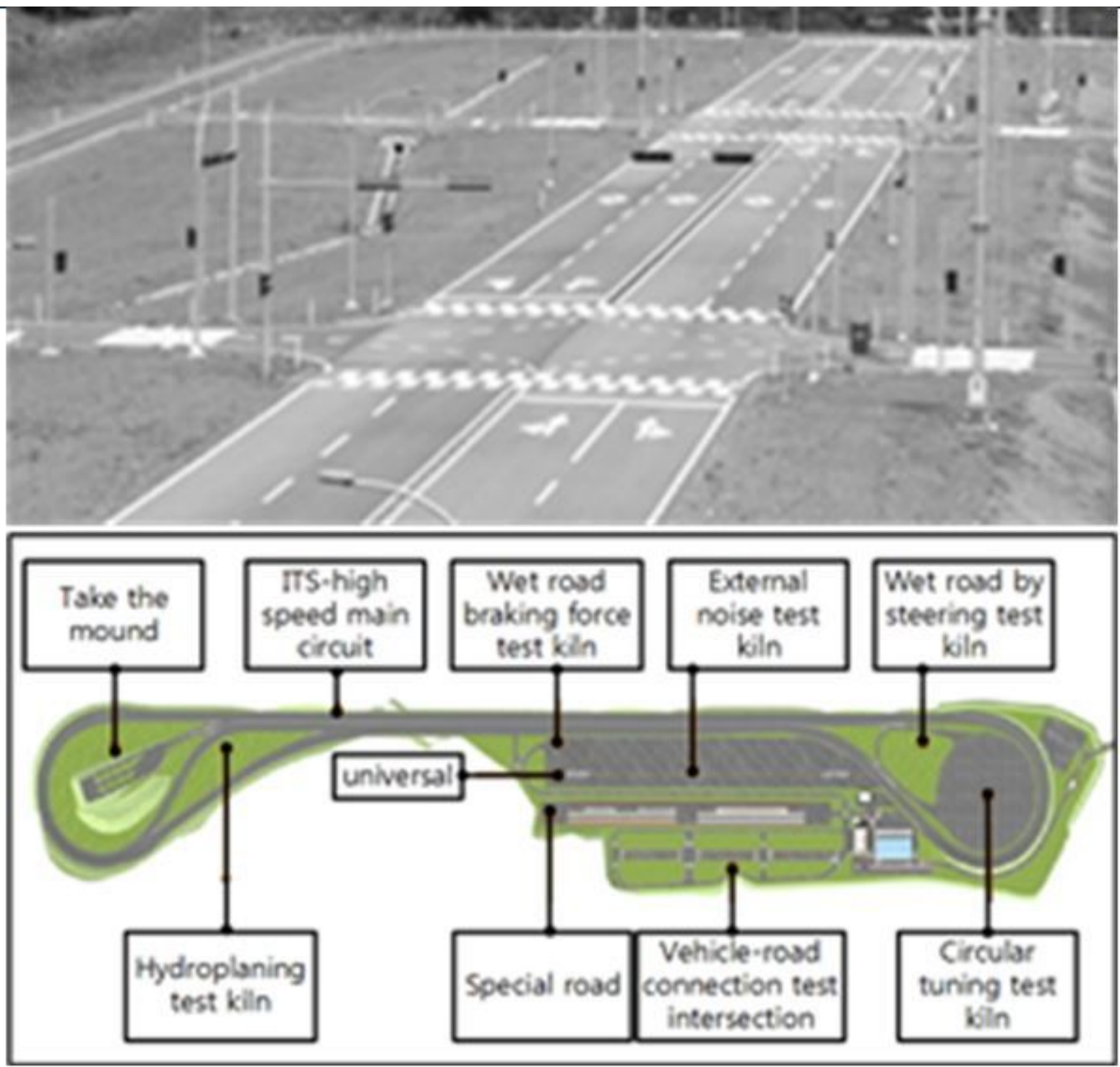

Figure 5

Vehicle-road connection test intersection of Korea Intelligent Automotive Parts Promotion Institute 


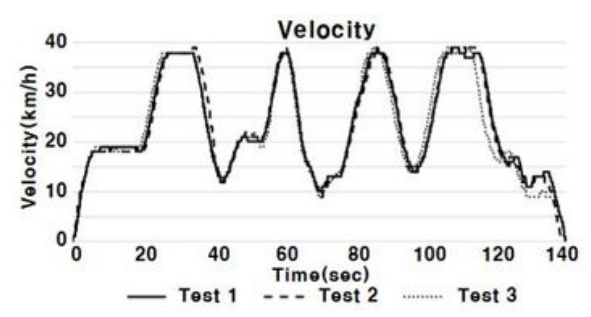

(a)

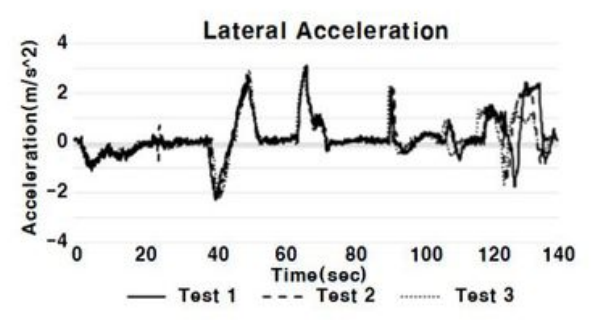

(d)

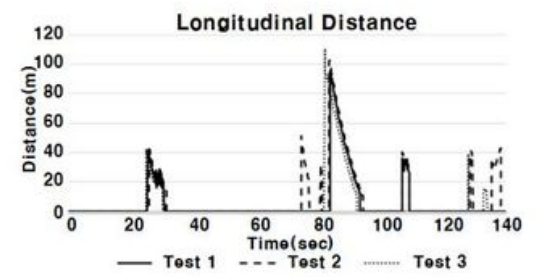

(g)

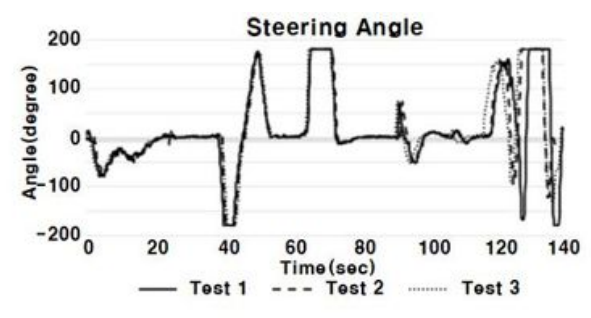

(b)

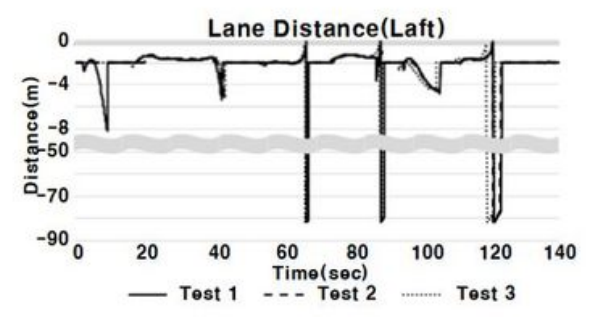

(e)

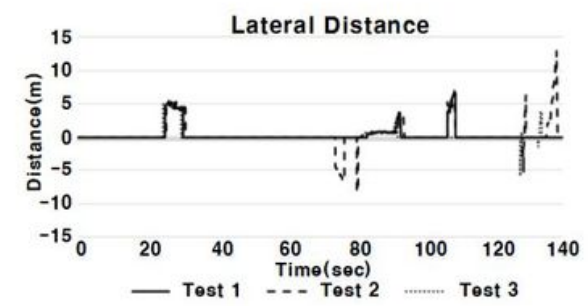

(h)

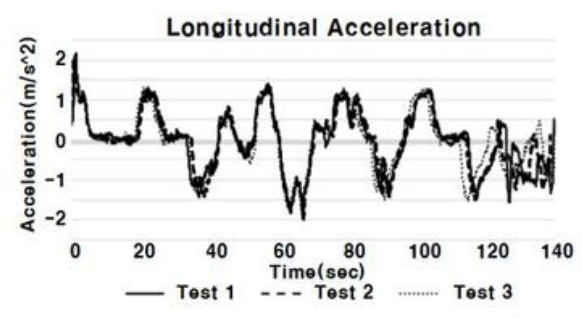

(c)

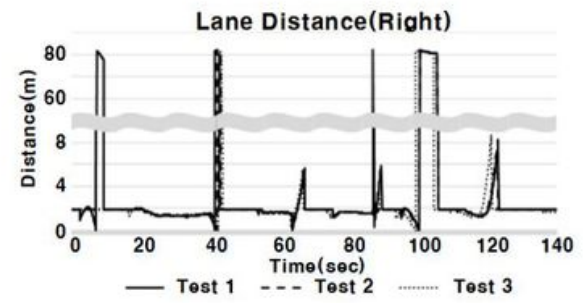

(f)

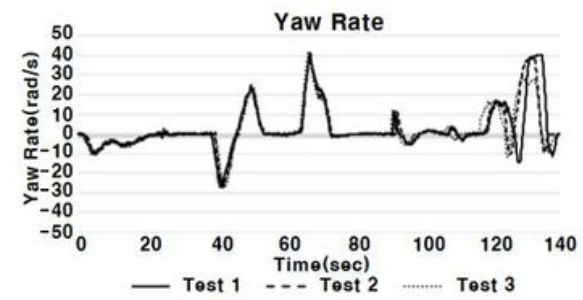

(i)

\section{Figure 6}

Test results(First Test Form) (a) speed, (b) steering angle (c) longitudinal acceleration (d) lateral acceleration $(e)$ left lane distance $(f)$ right lane distance $(g)$ longitudinal relative distance $(\mathrm{h})$ lateral relative distance (i) yaw rate 


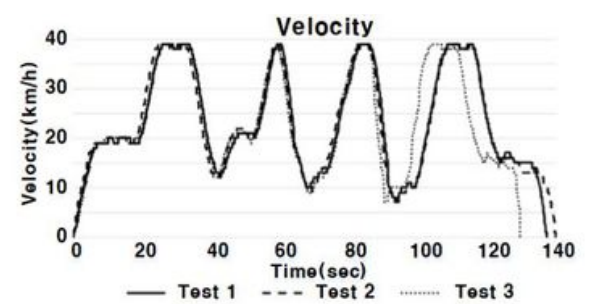

(a)

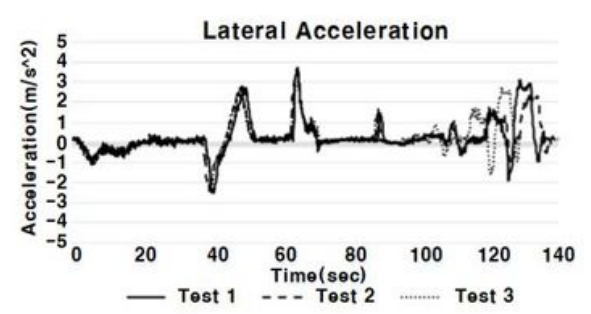

(d)

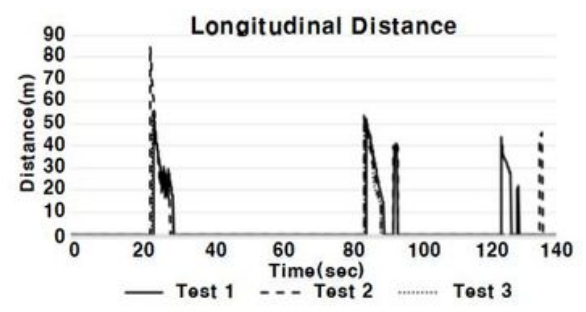

(g)

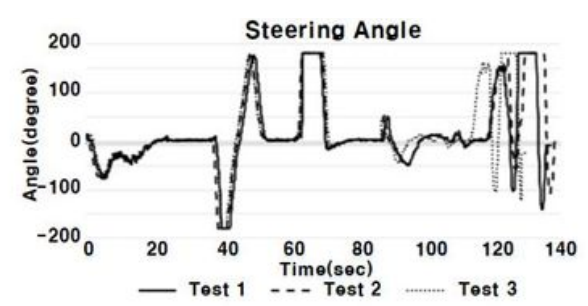

(b)

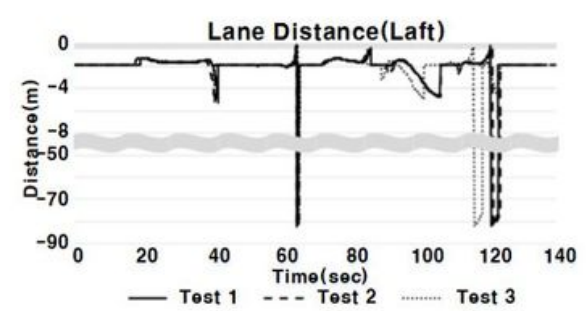

(e)

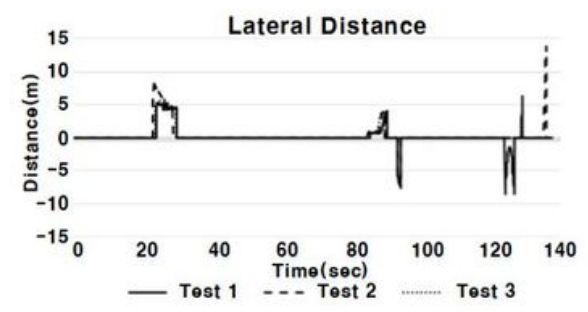

(h)

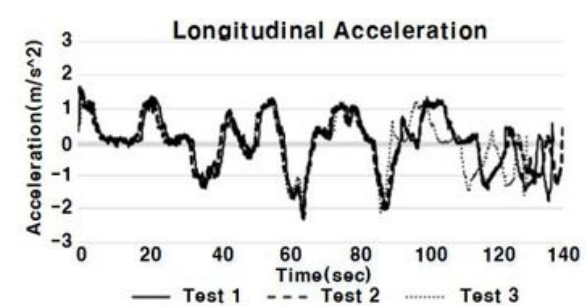

(c)

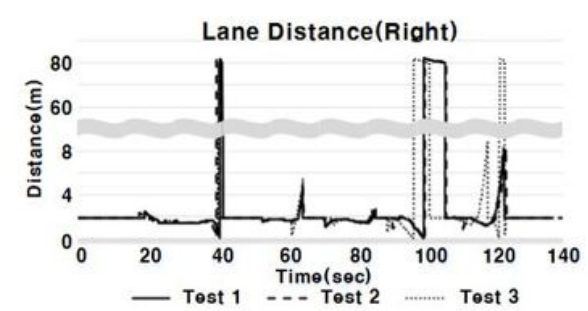

(f)

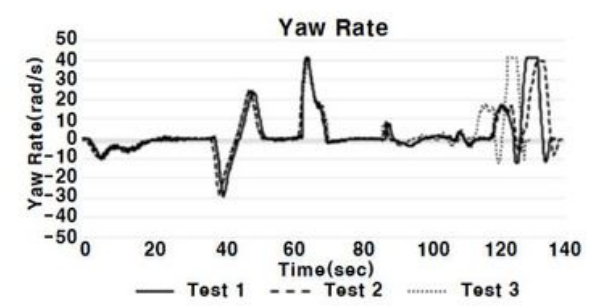

(i)

Figure 7

Test results(Second Test Form) (a) speed, (b) steering angle (c) longitudinal acceleration (d) lateral acceleration $(\mathrm{e})$ left lane distance $(\mathrm{f})$ right lane distance $(\mathrm{g})$ longitudinal relative distance $(\mathrm{h})$ lateral relative distance (i) yaw rate 


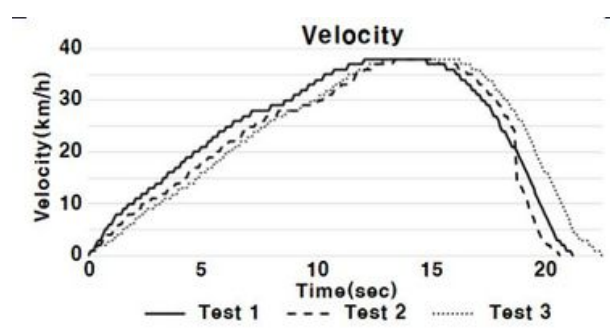

(a)

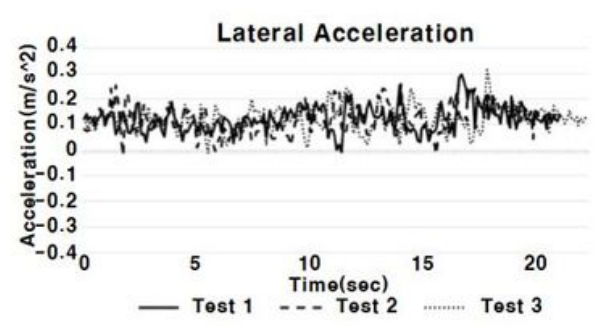

(d)

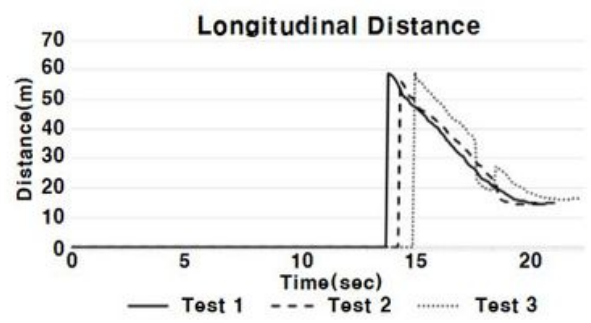

(g)

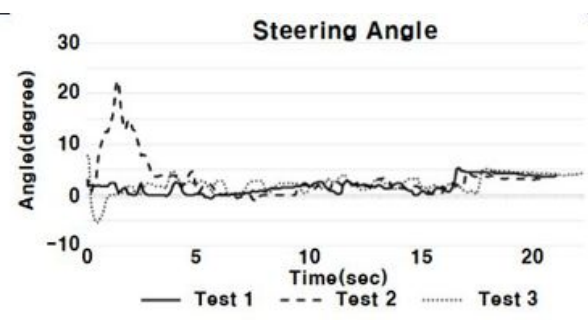

(b)

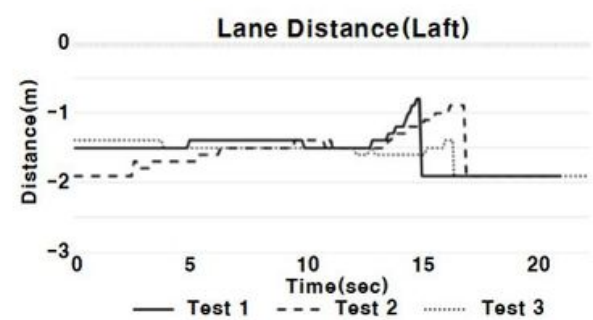

(e)

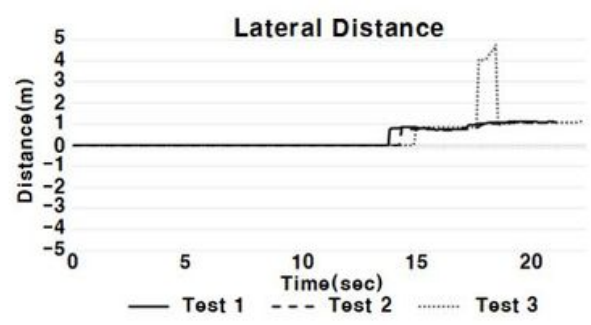

(h)

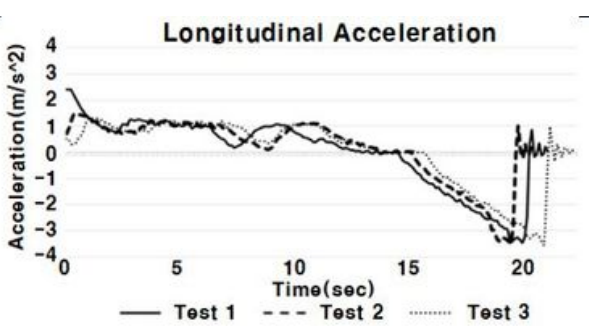

(c)

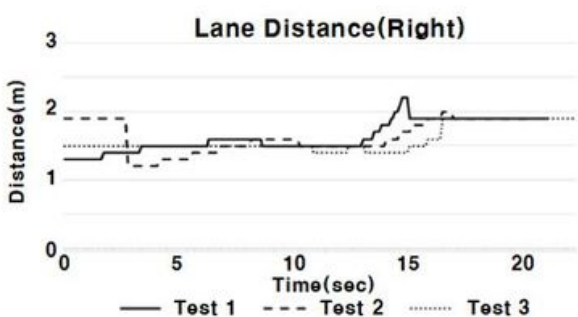

(f)

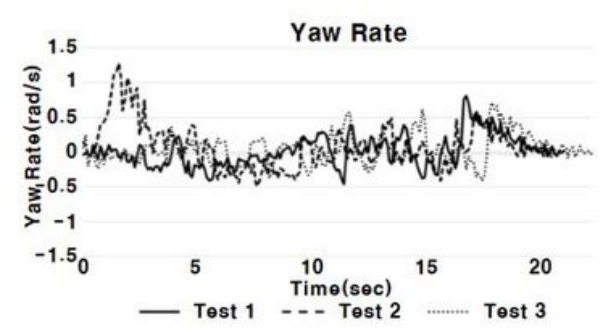

(i)

Figure 8

Test results(Third Test Form) (a) speed, (b) steering angle (c) longitudinal acceleration (d) lateral acceleration (e) left lane distance $(\mathrm{f})$ right lane distance $(\mathrm{g})$ longitudinal relative distance $(\mathrm{h})$ lateral relative distance (i) yaw rate 


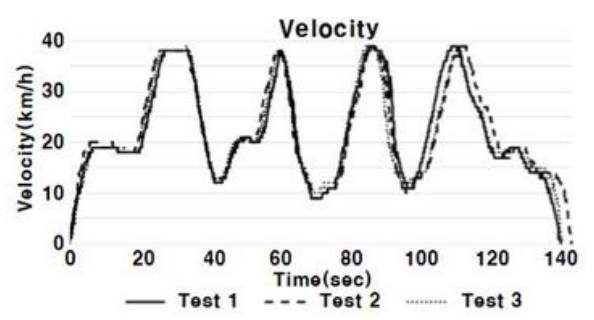

(a)

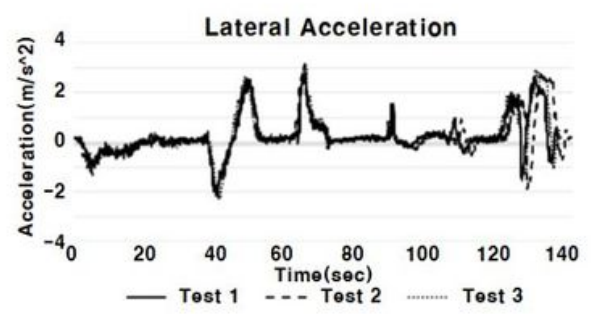

(d)

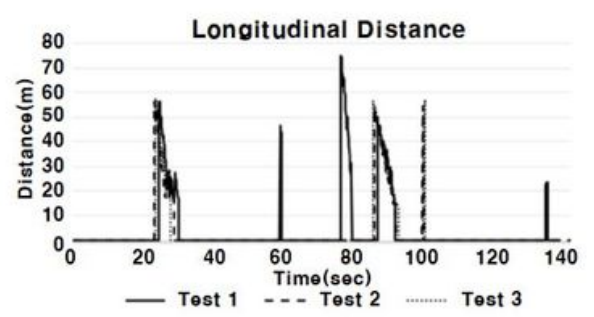

(g)

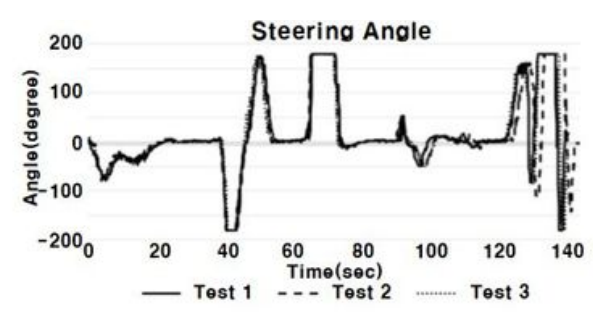

(b)

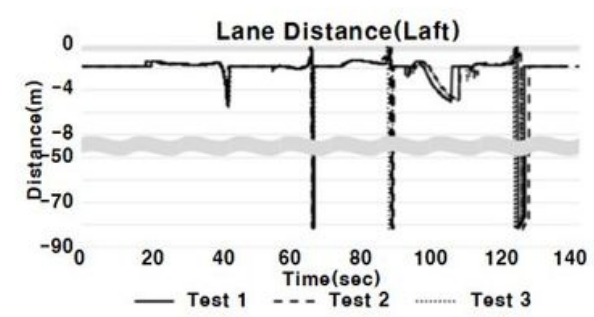

(e)

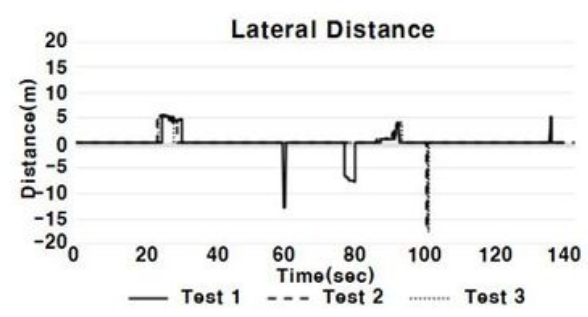

(h)

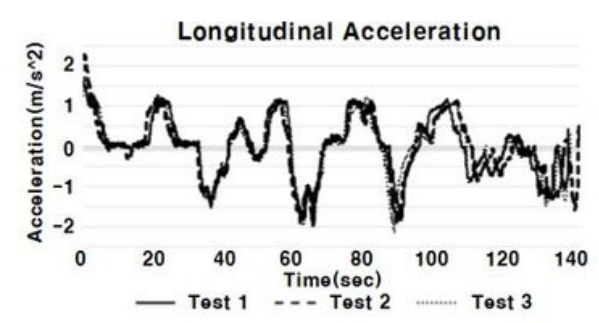

(c)

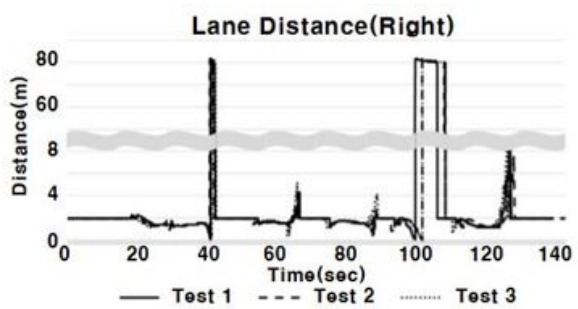

(f)

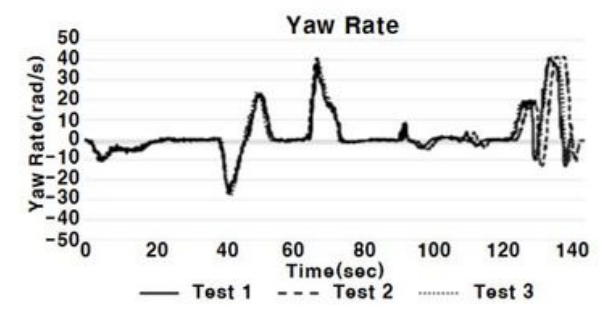

(i)

Figure 9

Test results(Fourth Test Form) (a) speed, (b) steering angle (c) longitudinal acceleration (d) lateral acceleration (e) left lane distance $(\mathrm{f})$ right lane distance $(\mathrm{g})$ longitudinal relative distance $(\mathrm{h})$ lateral relative distance (i) yaw rate 